\title{
Validity of self-reported height and weight among adolescents: the importance of reporting capability
}

\author{
Mette Rasmussen ${ }^{1 *}$, Bjørn E Holstein ${ }^{1}$, Ole Melkevik² and Mogens Trab Damsgaard
}

\begin{abstract}
Background: This study proposes a new approach for investigating bias in self-reported data on height and weight among adolescents by studying the relevance of participants' self-reported response capability. The objectives were 1) to estimate the prevalence of students with high and low self-reported response capability for weight and height in a self-administrated questionnaire survey among 11-15 year old Danish adolescents, 2) to estimate the proportion of missing values on self-reported height and weight in relation to capability for reporting height and weight, and 3) to investigate the extent to which adolescents' response capability is of importance for the accuracy and precision of self-reported height and weight. Also, the study investigated the impact of students' response capability on estimating prevalence rates of overweight.
\end{abstract}

Methods: Data was collected by a school-based cross-sectional questionnaire survey among students aged 11-15 years in 13 schools in Aarhus, Denmark, response rate $=89 \%, n=2100$. Response capability was based on students' reports of perceived ability to report weight/height and weighing/height measuring history. Direct measures of height and weight were collected by school health nurses.

Results: One third of the students had low response capability for weight and height, respectively, and every second student had low response capability for BMI. The proportion of missing values on self-reported weight and height was significantly higher among students who were not weighed and height measured recently and among students who reported low recall ability. Among both boys and girls the precision of self-reported height and weight tended to be lower than among students with low response capability. Low response capability was related to BMI (z-score) and overweight prevalence among girls. These findings were due to a larger systematic underestimation of weight among girls who were not weighed recently $(-1.02 \mathrm{~kg}, \mathrm{p}<0.0001)$ and among girls with low recall ability for weight $(-0.99 \mathrm{~kg}, \mathrm{p}=0.0024)$.

Conclusion: This study indicates that response capability may be relevant for the accuracy of girls' self-reported measurements of weight and height. Consequently, by integrating items on response capability in survey instruments, participants with low capability can be identified. Similar analyses based on other and less selected populations are recommended.

Keywords: Height/weight, Self-reports, Validity, Response capability, Adolescents

\section{Background}

Body Mass Index (BMI) $\left(\mathrm{kg} / \mathrm{m}^{2}\right)$ is a frequently used measure for estimating weight status e.g. [1]. In large population surveys, direct measurement of height and weight is often not feasible due to restrictions in financial resources. Instead, data are commonly collected by self-reports. Selfreported data on height and weight are compromised by a number of methodological issues. Study populations of

\footnotetext{
*Correspondence: mera@niph.dk

${ }^{1}$ National Institute of Public Health, University of Southern Denmark, Øster Farimagsgade 5A, Copenhagen K DK-1353, Denmark

Full list of author information is available at the end of the article
}

adolescents are often characterised by a substantial proportion of missing values on height and weight [2-4]. Further, weight is often under-reported [5-13] while height tends to be over-reported $[5,6,8,10,12,13]$. Consequently, BMI is frequently underestimated leading to misclassification as some overweight individuals are classified as being normal weight.

This paper proposes a new approach for studying bias in self-reported data about height and weight, namely to study the relevance of participants' self-reported response capability. The relevance of considering the

\section{Biomed Central}


regularity of adolescents weighing or measuring practises and their opportunities for weighing and measuring themselves have previously been highlighted $[7,14]$. However, the empirical research investigating the importance of weighing oneself for the capability for responding to survey questionnaires is scarce. De Vriendt (2009) and colleagues found that Belgian adolescents who weighed themselves during the past year reported their weight with a higher accuracy than those who did not [15]. Hauck and colleagues found that a large proportion of American Indian adolescents did not know their weight or height and about half of those who reported their weight and height were uncertain about the value [16].

As indicated by the previous studies, weighing and measuring practices may be important for the ability to provide valid information on weight and height. The proximity in time between weighing and height measuring and reporting the data may be particularly important during adolescence as most adolescents experience a substantial increase in both height and weight. Also, participants' response may be influenced by their ability to recall their height and weight. Therefore it may be useful to include items on weighing and height measuring history and perceived recall ability in survey instruments. This will allow results to be evaluated according to respondents' capability to respond. However, the relevance of collecting such data is dependent upon the extent to which response capability for height and weight indeed is associated with the level of precision (random errors) and accuracy (systematic errors) in the self- reported measures.

The aims of this study are 1) to estimate the prevalence of low response capability for weight and height in a school-based self-administrated questionnaire survey among a population of 11 to 15 year old Danish adolescents, 2) to estimate the proportion of missing values on self-reported height and weight in relation to capability for reporting height and weight, and 3) to investigate the extent to which adolescents' response capability influence the precision and accuracy in self-reported height and weight. Fourth and finally, the study aims to investigate the impact of students' response capability for estimating prevalence rates of overweight.

\section{Methods}

\section{Design}

Data are from the Aarhus School Survey, a school-based cross-sectional questionnaire survey conducted in the city of Aarhus, the second largest city in Denmark (314.000 inhabitants). The overall aim of the study was to investigate health, health behaviour, social relations and well-being of schoolchildren in Aarhus. The survey is an interim data collection of a nationally representative survey conducted every fourth year constituting the Danish contribution to the cross-national Health Behaviour in School-aged Children (HBSC) survey [1,17]. The HBSC survey collects data from schoolchildren aged 11, 13 and 15, and the same age groups were approached in the Aarhus School Survey.

\section{Sampling}

The Aarhus School Survey applied a strategic sampling procedure to ensure sufficient variability in socioeconomic position and ethnic background. Thirteen schools were included and all students at grade five, seven and nine were invited corresponding to the age groups of 11 , 13 and 15 years. A total of 2.100 students were included in the final data file corresponding to $99 \%$ of the students present on the day of data collection and $89 \%$ of the students enrolled in the sampled classes.

\section{Data collection}

The procedures for data collection resembled the procedures applied in the HBSC survey [1,17]. In each participating school, the school board, headmaster and students' council had approved the study and the school nurse had been informed. The students were asked to complete the questionnaire following a standard instruction from the teacher and to return their questionnaire in sealed envelopes in order to protect their anonymity.

Parts of the internationally standardised HBSC instrument were applied for measuring socio-demographic factors, health, weight and height, health behaviours, well-being and social relations [1]. Additional items were developed for the survey including items on history of weighing and height measuring and perceived weight and height recall ability. We conducted a qualitative pilot study based on focus group discussions with students who answered the draft questionnaire. Based on the experiences from the pilot we developed the final version of the questionnaire.

\section{Measurements}

Self-reports of weight and height were collected by the items "How much do you weigh without clothes?" (in kg.) and "How tall are you without shoes?" (in $\mathrm{cm}$.).

The following questions on response capability were placed apart from the two first questions on weight and height in the questionnaire.

We obtained information on weighing and height measuring history by two items: 'When were you last weighed/height measured? with the response categories: a) within the past week, b) within the past month, c) within the past half year, d) more than half a year ago, and e) don't remember'. We dichotomised weighing history into being weighed 'within the past month' (recently) versus the combined 'more than one month ago' 
and 'don't remember' categories (not recently). Height measuring history was dichotomised into being measured 'within the past half year' (recently) versus the combined 'more than half a year ago' and 'don't remember' (not recently).

Perceived recall ability was measured by the following two items: 'Many children and adolescents have trouble remembering their weight/height. How well do you remember your weight/height?' with the following response categories: a) exactly, b) approximately, c) not very well, and c) don't remember it. We dichotomised weight and height recall ability into 'exactly' and 'approximately' (high) versus 'not very well' and 'don't remember' (low).

We defined two four-category combined variables on response capability for weight and height, respectively, by combining the variables on measuring history (recently/not recently) and perceived recall ability (high/ low). Also, a dichotomized combined variable on BMI response capability was constructed. High BMI response capability included students who were recently weighed and height measured and who had also high recall ability for weight and height. Students not fulfilling these requirements were categorised by low BMI response capability. Students with missing data on weighing/height measuring history or recall ability were coded missing in the combined variables.

Parents' occupational social class was measured by students' reports of their parents' occupation, coded into social class and categorised according to highest ranking parent into 'high', 'medium,' 'low', and 'unclassifiable'. Family structure was based on students' reports on who they live with and categorised into 'traditional family' (two biological parents), 'single-parent family' (one single biological parent), 'reconstructed family', and missing information. Students living in other family structures were low in number $(n=15)$ and were left out of analyses. Further, we categorised migration status based on students' reports on own and parents' place of birth and students were classified into 'Danish', 'immigrants' and 'descendants of immigrants'.

After students had completed the questionnaire survey they were invited for a consultation where direct weight and height were measured to the nearest $0.1 \mathrm{~kg}$ and $0.5 \mathrm{~cm}$ by two school health nurses at the school settings following standardised instructions. The consultations were conducted within one to three weeks following the questionnaire survey. The same weighing balance (model Seca 882) was applied for collection of all data on weight. Students were weighed wearing underclothes or the minimum clothes acceptable to them. The types of clothing were recorded. Students' height was measured standing without shoes under standardised instructions ensuring perpendicular measures at a correctly placed height measuring scale. Following data collection, data on weights were corrected for students wearing more than underclothes $(n=860)$ by extracting mean weights for typical pants, skirts and long-sleeved tops. The individual extraction weight of the clothe item was done according to the student's measured height in one of three height groups, based on the total height distribution of the sample.

Table 1 describes the distribution of variables used in analyses.

\section{Ethical issues}

The study complies with the Helsinki II declaration. In Denmark there is no formal agency for approval of population based surveys and the schools decide autonomously whether to participate in such surveys. The survey was conducted under full confidentiality, informed consent and voluntary participation.

\section{Statistical analyses}

BMI was computed for each individual $\left(B M I=\mathrm{kg} / \mathrm{m}^{2}\right)$. The meaning of BMI-values varies depending on a child's age and gender and BMI-values were therefore transformed into z-scores based on data tables and formulas provided by WHO [18]. Overweight was defined by $\mathrm{z}$-score $\geq 1$ according to the guidelines by WHO [18].

We used Chi-square test to test for significant differences in pair-wise comparisons of distributions. Paired-sample t-tests were conducted in order to detect significant differences in means between the direct measures and self-reported data on weight and height, respectively.

Systematic measurement error was studied by multivariate analyses of variance [19]. Here, the association between the independent variables weighing/height measure history, recall ability for weight/height, response capability for weight/height and BMI response capability and the dependent variables difference between self-reported and direct measures of weight, height and BMI z-score were analysed, respectively. Analyses were conducted in two steps: First, analyses stratified by gender and adjusted by age, family occupational social class, family structure and migration status were completed. A random effect of school was included to adjust for the design effect introduced by the applied cluster sampling approach [20]. From the literature it is evident that underestimation of weight is especially observed among girls who consider themselves to be too fat $[13,21]$ and that overweight and obese adolescents tend to underreport their weight compared to normal weight adolescents [9,10,22-24]. The literature also documents that taller adolescents tend to underestimate their height whereas shorter adolescents tend to overestimate height [25]. These findings suggest social desirability bias in adolescents' reports of height and weight. 
Table 1 Distribution of participants according to the applied variables by gender

\begin{tabular}{cccc}
\hline $\begin{array}{c}\text { Total study } \\
\text { population } \\
(\mathrm{N}=2100)\end{array}$ & $\mathrm{N}=1031$ & $\mathrm{~N}=1069$ \\
$\mathrm{n}(\%)$ & $\mathrm{n}(\%)$ & $\mathrm{n}(\%)$ \\
\hline
\end{tabular}

\section{Age}

11 years

13 years

15 year

Last weighed...

Within past week

Within past month

Within past half year

Since longer

Cannot remember

Missing

Last height measured...

Within past week

Within past month

Within past half year

Since longer

Cannot remember

Missing

Can remember weight...

Exactly

Approximately

Not very well

Don't remember

Missing

Can remember height...

Exactly

Approximately

Not very well

Don't remember

Missing

Response capability for weight

Weighed recently + high

recall ability

Weighed recently + low

recall ability

Not weighed recently + high

recall ability

Not weighed recently + low recall ability

Missing

Response capability for height

Measured recently + high recall ability

$\begin{array}{lll}755(36.0) & 366(35.5) & 389(36.4) \\ 775(36.9) & 378(36.7) & 397(37.1) \\ 570(27.1) & 287(27.8) & 283(26.5)\end{array}$

707 (33.7) $315(30.6) \quad 392(36.7)^{*}$

$725(34.5) \quad 351(34.0) \quad 374(35.0)$

$354(16.9) \quad 199(19.3) \quad 155(14.5)$

$86(4.1) \quad 45(4.4) \quad 41(3.8)$

$200(9.5) \quad 105(10.2) \quad 95(8.9)$

$28(1.3) \quad 16(1.6) \quad 12(1.1)$

$315(15.0) \quad 171(16.6) \quad 144(13.5)$

$634(30.2) \quad 304(29.5) \quad 330(30.9)$

678 (32.3) 331 (32.1) $347(32.5)$

$205(9.8) \quad 91(8.8) \quad 114(10.7)$

$246(11.7) \quad 122(11.8) \quad 124(11.6)$

$22(1.1) \quad 12(1.2) \quad 10(0.9)$

$540(25.7) \quad 272(26.4) \quad 268(25.1)$

$1147(54.6) \quad 556(53.9) \quad 591(55.3)$

$246(11.7) \quad 115(11.2) \quad 131(12.3)$

$133(6.3) \quad 72(7.0) \quad 61(5.7)$

$34(1.6) \quad 16(1.6) \quad 18(1.7)$

$489(23.3) \quad 224(21.7) \quad 265(24.8)^{*}$

$1185(56.4) \quad 587(56.9) \quad 598(55.9)$

$271(12.9) \quad 127(12.3) \quad 144(13.5)$

$132(6.3) \quad 82(8.0) \quad 50(4.7)$

$23(1.1) \quad 11(1.1) \quad 12(1.1)$

$1317(62.7) \quad 617(59.8) \quad 700(65.5)^{*}$

$109(5.2) \quad 47(4.6) \quad 62(5.8)$

$367(17.5) \quad 209(20.3) \quad 158(14.8)$

$269(12.8) \quad 140(13.6) \quad 129(12.1)$

$38(1.8) \quad 18(1.8) \quad 20(1.9)$

$1420(67.6) \quad 698(67.7) \quad 772(67.5)$
Table 1 Distribution of participants according to the applied variables by gender (Continued)

\begin{tabular}{lccc}
\hline $\begin{array}{l}\text { Measured recently + low } \\
\text { recall ability }\end{array}$ & $203(9.7)$ & $107(10.4)$ & $96(9.0)$ \\
Not measured recently + high & $251(12.0)$ & $112(10.9)$ & $139(13.0)$
\end{tabular}

recall ability

Not measured recently + low recall ability

Missing

Response capability combined

for height and weight

High

Low

Missing

Family occupational social class

High

Middle

Low

Un-classifiable

Missing

Family structure

Traditional family

$198(9.4) \quad 101(9.8) \quad 97(9.1)$

$28(1.3) \quad 13(1.3) \quad 15(1.4)$

Reconstructed family

Single-parent family

Other

Missing

$$
\begin{array}{ccc}
1023(48.7) & 491(47.6) & 532(49.8) \\
1026(48.9) & 517(50.2) & 509(47.6) \\
51(2.4) & 23(2.2) & 28(2.6)
\end{array}
$$

$902(43.0) \quad 449(43.6) \quad 453(42.4)^{*}$

559 (26.6) $264(25.6) \quad 295$ (27.6)

304 (14.5) $131(12.7) \quad 173(16.2)$

$297(14.1) \quad 166(16.1) \quad 131(12.3)$

$38(1.8) \quad 21(2.0) \quad 17(1.6)$

$1160(55.2) \quad 585(56.7) \quad 575(53.8)$

191 (9.1) $\quad 80(7.8) \quad 111(10.4)$

$422(20.1) \quad 206(20.0) \quad 216(20.2)$

$15(0.7) \quad 5(0.5) \quad 10(0.9)$

$312(14.9) \quad 155(15.0) \quad 157(14.7)$

Migration status

Danish

1734 (82.6) 858 (83.2) $876(81.9)$

Decendants

$236(11.2) \quad 104(10.1) \quad 132(12.4)$

Immigrants

$109(5.2) \quad 55(5.3) \quad 54(5.1)$

Missing

$21(1.0) \quad 14(1.4) \quad 7(0.7)$

* Significant difference in distribution between boys and girls, tested by chi square test $(p<0.05)$ (not accounting for the design effect caused by the applied cluster sampling). Missing values are not included in analyses.

The concept of response capability and the applied operationalization may potentially overlap with the concept of social desirability. Therefore, secondly analyses also adjusted by measured weight and height, respectively, were conducted.

Finally, prevalence of overweight was described by BMI response capability.

Generally, since marked differences were observed between boys and girls, all analyses were therefore conducted stratified by gender. The modifying effect of gender was also tested by inclusion of an interaction term in the multivariate analyses. All statistical analyses were conducted in SAS version 9.1 (SAS Institute, Cary, NC). 


\section{Results}

Not having been height measured recently and low recall ability for height and weight were each observed among approximately one fifth of the study population while one third had not been weighed recently. The proportion of students with high response capability for weight and height was $62.7 \%$ and $67.6 \%$ respectively. The proportion of students with high capability for reporting BMI was $48.7 \%$ (Table 1 ).

The proportion of missing values on weight and height was significantly higher among students who had not been weighed and height measured recently and among students who reported low recall ability. Analyses of the distribution of missing values by the combined measure of response capability for weight showed that the proportion of missing values was high when students reported low recall ability irrespectively of when they were last weighed (approximately 20\% compared to $5-10 \%$ in the groups of students with high recall ability). The same pattern was seen for the combined measure of response capability for height (data not shown).

Table 2 compares self-reported and direct measures of weight by weighing history, recall ability for weight and response capability for weight. Generally, significant underestimation was seen among both boys and girls (boys: $-0.81 \mathrm{~kg}, \mathrm{SD}=4.95$; girls: $-1.82 \mathrm{~kg}, \mathrm{SD}=3.15$ ). Analyses stratified by weighing history showed a significant underestimation of weight both among girls who are weighed recently and those who are not. The largest mean underestimation was observed among girls who are not weighed recently $(-2.70 \mathrm{~kg}, \mathrm{SD}=4.11)$. Among

Table 2 Comparisons of self-reported and directly measured weight among 11- to 15 year old adolescents by weighing history, recall ability for weight and response capability for weight

\begin{tabular}{|c|c|c|c|c|c|c|c|c|c|}
\hline & \multirow[t]{2}{*}{$\mathrm{N}$} & \multicolumn{2}{|c|}{ Weight/self-reported (kg) } & \multicolumn{2}{|c|}{ Weight/direct (kg) } & \multicolumn{4}{|c|}{ Difference for weight $(\mathbf{k g})$} \\
\hline & & Mean & SD & Mean & SD & Mean & SD & $95 \% \mathrm{Cl}$ & P value ${ }^{*}$ \\
\hline Boys & 839 & 50.98 & 13.14 & 51.79 & 13.29 & -0.81 & 4.95 & $-1.15 ;-0.81$ & $<0.0001$ \\
\hline Girls & 845 & 47.63 & 10.07 & 49.45 & 10.60 & -1.82 & 3.15 & $-2.03 ;-1.61$ & $<0.0001$ \\
\hline \multicolumn{10}{|l|}{ Weighing history } \\
\hline \multicolumn{10}{|l|}{ Boys } \\
\hline Weighed recently & 572 & 50.74 & 13.12 & 51.64 & 13.30 & -0.90 & 4.24 & $-1.24 ;-0.55$ & $<0.0001$ \\
\hline Not weighed recently & 259 & 51.51 & 13.28 & 52.17 & 13.37 & -0.67 & 6.27 & $-1.43 ;-0.10$ & 0.0893 \\
\hline \multicolumn{10}{|l|}{ Girls } \\
\hline Weighed recently & 645 & 47.69 & 10.09 & 49.26 & 10.41 & -1.57 & 2.64 & $-1.77 ;-1.36$ & $<0.0001$ \\
\hline Not weighed recently & 195 & 47.29 & 10.01 & 49.99 & 11.22 & -2.70 & 4.11 & $-3.28 ;-2.12$ & $<0.0001$ \\
\hline \multicolumn{10}{|l|}{ Recall ability for weight } \\
\hline \multicolumn{10}{|l|}{ Boys } \\
\hline High recall ability & 718 & 50.64 & 13.33 & 51.40 & 13.40 & -0.76 & 4.94 & $-1.12 ;-0.40$ & $<0.0001$ \\
\hline Low recall ability & 112 & 53.13 & 11.95 & 54.34 & 12.58 & -1.21 & 5.09 & $-2.17 ;-0.26$ & 0.0131 \\
\hline \multicolumn{10}{|l|}{ Girls } \\
\hline High recall ability & 726 & 47.54 & 10.00 & 49.14 & 10.38 & -1.61 & 2.83 & $-1.81 ;-1.40$ & $<0.0001$ \\
\hline Low recall ability & 109 & 48.26 & 10.65 & 51.31 & 11.84 & -3.06 & 4.45 & $-3.91 ;-2.21$ & $<0.0001$ \\
\hline \multicolumn{10}{|l|}{ Response capability for weight } \\
\hline \multicolumn{10}{|l|}{ Boys } \\
\hline Weighed recently + high recall ability & 538 & 50.61 & 13.15 & 51.49 & 13.36 & -0.88 & 4.25 & $-1.24 ;-0.52$ & $<0.0001$ \\
\hline Weighed recently + low recall ability & 32 & 53.07 & 12.83 & 54.10 & 12.57 & -1.03 & 4.21 & $-2.55 ; 0.49$ & 0.1757 \\
\hline Not weighed recently + high recall ability & 179 & 50.78 & 13.91 & 51.16 & 13.59 & -0.39 & 6.62 & $-1.36 ; 0.59$ & 0.4343 \\
\hline Not weighed recently + low recall ability & 80 & 53.15 & 11.66 & 54.44 & 12.66 & -1.29 & 5.43 & $-2.50 ;-0.08$ & 0.0373 \\
\hline \multicolumn{10}{|l|}{ Girls } \\
\hline Weighed recently + high recall ability & 599 & 47.79 & 9.99 & 49.21 & 10.20 & -1.42 & 2.39 & $-1.61 ;-1.23$ & $<0.0001$ \\
\hline Weighed recently + low recall ability & 42 & 46.80 & 11.62 & 50.35 & 13.37 & -3.56 & 4.44 & $-4.94 ;-2.17$ & $<0.0001$ \\
\hline Not weighed recently + high recall ability & 126 & 46.20 & 9.93 & 48.84 & 11.30 & -2.64 & 3.94 & $-3.33,-1.94$ & $<0.0001$ \\
\hline Not weighed recently + low recall ability & 67 & 49.17 & 9.98 & 51.92 & 10.83 & -2.75 & 4.46 & $-3.84,-1.66$ & $<0.0001$ \\
\hline
\end{tabular}

\footnotetext{
* Paired $T$-test.
} 
boys, underestimation of weight was only significant among those who are weighed recently $(-0.90 \mathrm{~kg}, \mathrm{SD}=$ 4.24). For both boys and girls a significant underestimation of weight was observed both among students with high recall ability and students with low recall ability. Mean underestimations were larger among students with low recall ability. Analyses stratified by combined information on student weighing history and recall ability for weight showed varying patterns by gender. Among boys significant underestimation was only observed in the combination 'being weighed recently + high recall ability' $(-0.88, \quad \mathrm{SD}=4.25)$ and in the combination 'not being weighed recently + low recall ability' $(-1.29, \mathrm{SD}=5.43)$. Among girls significant underestimation was observed in all four combinations. The smallest underestimation was observed among girls 'being weighed recently + high recall ability' $(-1.42, \mathrm{SD}=2.39)$. In analyses of all operationalizations of response capability the largest standard deviation of mean difference for weight were seen among students with low response capability indicating a lower reporting precision (random measurement error).

Table 3 compares self-reported and direct measures of height by height measuring history, recall ability for height and response capability for height. There was a significant overestimation among boys $(+0.25 \mathrm{~cm}, \mathrm{SD}=$ 3.47) but not among girls. For both boys and girls, analyses stratified by height measuring history showed insignificant overestimations among both students measured recently and students not measured recently. Analyses stratified by recall ability for height revealed a significant overestimation among both boys and girls with high

Table 3 Comparisons of self-reported and direct measures of height among 11- to 15 year old adolescents by height measuring history, recall ability for height and response capability for height

\begin{tabular}{|c|c|c|c|c|c|c|c|c|c|}
\hline & \multirow[t]{2}{*}{$\mathbf{N}$} & \multicolumn{2}{|c|}{ Height/self-reported $(\mathrm{cm})$} & \multicolumn{2}{|c|}{ Height/direct $(\mathrm{cm})$} & \multicolumn{4}{|c|}{ Difference for height (cm) } \\
\hline & & Mean & SD & Mean & SD & Mean & SD & $95 \% \mathrm{Cl}$ & $P$ value \\
\hline Boys & 839 & 164.51 & 13.11 & 164.26 & 12.77 & 0.25 & 3.47 & $0.02 ; 0.49$ & 0.0340 \\
\hline Girls & 886 & 160.37 & 9.53 & 160.22 & 9.02 & 0.15 & 2.81 & $-0.04 ; 0.34$ & 0.1108 \\
\hline
\end{tabular}

Height measuring history

Boys

$\begin{array}{rrr}\text { Measured recently } & 679 & 164.12 \\ \text { Not measured recently } & 155 & 166.27\end{array}$

$\begin{array}{ll}13.21 & 163.89 \\ 12.64 & 165.79\end{array}$

12.96
11.99

$\begin{array}{lll}0.23 & 3.25 & -0.02 ; 0.47 \\ 0.48 & 4.27 & -0.20 ; 1.15\end{array}$

0.0669

Girls

$\begin{array}{rrr}\text { Measured recently } & 692 & 160.11 \\ \text { Not measured recently } & 190 & 161.31\end{array}$

9.60
9.33

159.96
161.09

9.18
8.45

$\begin{array}{llll}0.15 & 2.62 & -0.05 ; 0.34 & 0.1427 \\ 0.22 & 3.42 & -0.27 ; 0.71 & 0.3713\end{array}$

Recall ability for height

Boys

$\begin{array}{lll}\text { High recall ability } & 707 & 164.62 \\ \text { Low recall ability } & 127 & 163.81\end{array}$

$\begin{array}{lcccccc}13.36 & 164.28 & 13.02 & 0.34 & 3.21 & 0.11 ; 0.58 & 0.0046 \\ 11.87 & 164.00 & 11.59 & -0.19 & 4.70 & -1.02 ; 0.63 & 0.6416 \\ & & & & & & \\ 9.59 & 160.20 & 9.21 & 0.19 & 2.56 & 0.01 ; 0.38 & 0.0409 \\ 9.29 & 160.17 & 8.02 & -0.01 & 3.91 & -0.68 ; 0.66 & 0.9788\end{array}$

Response capability for height

Boys

\begin{tabular}{|c|c|c|c|c|c|c|c|c|c|}
\hline Measured recently + high recall ability & 612 & 164.38 & 13.39 & 164.09 & 13.10 & 0.29 & 3.12 & $0.04 ; 0.54$ & 0.0225 \\
\hline Measured recently + low recall ability & 66 & 161.77 & 11.23 & 162.11 & 11.65 & -0.34 & 4.23 & $-1.38 ; 0.70$ & 0.5145 \\
\hline Not measured recently + high recall ability & 94 & 166.43 & 12.96 & 165.62 & 12.49 & 0.81 & 3.54 & $0.08 ; 1.53$ & 0.0291 \\
\hline Not measured recently + low recall ability & 61 & 166.02 & 12.23 & 166.06 & 11.27 & -0.04 & 5.19 & $-1.37 ; 1.29$ & 0.9569 \\
\hline \multicolumn{10}{|l|}{ Girls } \\
\hline Measured recently + high recall ability & 631 & 160.08 & 9.74 & 159.92 & 9.38 & 0.16 & 2.49 & $-0.03 ; 0.36$ & 0.1052 \\
\hline Measured recently + low recall ability & 60 & 160.50 & 7.97 & 160.42 & 6.90 & 0.08 & 3.66 & $-0.86 ; 1.03$ & 0.8605 \\
\hline Not measured recently + high recall ability & 115 & 162.09 & 8.55 & 161.73 & 8.12 & 0.36 & 2.89 & $-0.17 ; 0.89$ & 0.1842 \\
\hline Not measured recently + low recall ability & 73 & 159.87 & 10.30 & 159.96 & 8.88 & -0.09 & 4.12 & $-1.05 ; 0.88$ & 0.8607 \\
\hline
\end{tabular}


recall ability (boys: $+0.34 \mathrm{~cm}, \mathrm{SD}=3.21$; girls: $+0.19 \mathrm{~cm}$, $\mathrm{SD}=2.56$ ). Analyses stratified by combined information on student height measuring history and recall ability for height showed significant overestimation among boys in the group 'measured recently + high recall ability' $(+0.29 \mathrm{~cm}, \mathrm{SD}=3.12)$ and in the group 'not being measured recently + high recall ability' $(+0.81 \mathrm{~cm}, \mathrm{SD}=3.54)$. Among girls, no significant differences were observed between self-reports and direct measures in any of the four groups. In analyses of all operationalizations of response capability the largest standard deviation of mean difference for height were seen among students with low response capability indicating a larger random measurement error.

Table 4 presents mean difference in BMI z-score based on self-reported and direct measures of weight and height by BMI response capability. Significant underestimations of BMI z-scores were observed for both students with high and low BMI response capability. Especially among girls, underestimation of BMI z-scores was larger among students with low BMI response capability $\left(-0.34 \mathrm{~kg} / \mathrm{m}^{2}, \mathrm{SD}=0.61\right)$ than high BMI response capability $\left(-0.23 \mathrm{~kg} / \mathrm{m}^{2}, \mathrm{SD}=0.45\right)$. A larger random measurement error was observed among students with low response capability.

Table 5 presents the multivariate analyses. Model 1, adjusting for age, family occupational social class, family structure and migration showed that among girls significantly larger underestimation of weight was observed among students not weighed recently $(B=-1.20 \mathrm{~kg}, \mathrm{p}>$ 0.0001 , interaction with gender: $\mathrm{p}=0.0015)$. Also among girls, low recall ability was associated with significantly larger underestimation of weight $(B=-1.39 \mathrm{~kg}, \mathrm{p}>$ 0.0001). Compared to girls 'being weighed recently + having high recall ability' all three remaining combinations of response capability for weight significantly underestimated weight (significant interaction with gender: $\mathrm{p}=0.0033$ ). Finally, among girls, low BMI response capability was associated with an underestimation of BMI z-score of $-0.13(\mathrm{p}=0.0019)$ (significant interaction with gender: $p=0.0105)$. The multivariate analyses showed no significant associations among boys. No additional significant interactions with gender were identified. In model 2, adjustment for measured height and weight were also included. Generally, a reduction in estimates was observed. Among girls the estimate for weighing history and recall ability for weight were reduced to $\mathrm{B}=-1.02$ and $\mathrm{B}=-0.99$, respectively. No changes in directions of associations or levels of significance were observed.

Table 6 presents overweight prevalence based on selfreports and direct measures by BMI response capability. Among boys, the difference in absolute underestimation of overweight prevalence between students with low and high BMI response capability was 0.58 percentage points being highest among boys with high response capability. Among girls, the difference constituted 1.33 percentage points with the underestimation being largest among girls with low response capability. Generally, the overweight prevalence was higher among students not measured recently compared to those measured recently and among student with low recall ability compared to students with high recall ability (data not shown). This is reflected in table 6 showing that the overweight prevalence was highest among students with low BMI response capability.

\section{Discussion}

The presented results from a Danish population of school children aged 11 to 15 showed that approximately one third of the students have low response capability for weight and height, respectively. Every

Table 4 Comparisons of z-scores based on self-reported and direct measures of weight and height among 11- to 15 year old adolescents by response

\begin{tabular}{|c|c|c|c|c|c|c|c|c|c|c|}
\hline & & \multirow[t]{2}{*}{$\mathbf{N}$} & \multicolumn{2}{|c|}{ z-score/self-reported } & \multicolumn{2}{|c|}{ z-score/direct } & \multicolumn{4}{|c|}{ Difference for z-score } \\
\hline & & & Mean & SD & Mean & SD & Mean & SD & $95 \% \mathrm{Cl}$ & P value* \\
\hline Boys & & 791 & -0.22 & 1.03 & -0.08 & 1.01 & -0.14 & 0.70 & $-0.19 ;-0.09$ & $<0.0001$ \\
\hline Girls & & 815 & -0.40 & 0.94 & -0.12 & 0.95 & -0.28 & 0.53 & $-0.31 ;-0.24$ & $<0.0001$ \\
\hline \multicolumn{11}{|c|}{ BMI Response capability** } \\
\hline \multicolumn{11}{|l|}{ Boys } \\
\hline & High & 419 & -0.28 & 1.00 & -0.11 & 0.99 & -0.18 & 0.62 & $-0.24 ;-0.12$ & $<0.0001$ \\
\hline & Low & 360 & -0.16 & 1.06 & -0.04 & 1.06 & -0.12 & 0.80 & $-0.20 ;-0.04$ & 0.0053 \\
\hline \multicolumn{11}{|l|}{ Girls } \\
\hline & High & 458 & -0.40 & 0.95 & -0.17 & 0.93 & -0.23 & 0.45 & $-0.27 ;-0.19$ & $<0.0001$ \\
\hline & Low & 343 & -0.39 & 0.93 & -0.05 & 0.97 & -0.34 & 0.61 & $-0.41 ;-0.28$ & $<0.0001$ \\
\hline
\end{tabular}

\footnotetext{
* Paired T-test.

**High combined response capability $=$ measured recently + high recall ability for height + weighed recently + high recall ability for weight, Low combined response capability = remaining categories.
} 
Table 5 Multivariate analyses of variance of associations between response capability and difference between selfreported and directly measured weight, height and BMI

\begin{tabular}{|c|c|c|c|c|c|c|c|c|}
\hline & \multicolumn{4}{|c|}{ Model 1* } & \multicolumn{4}{|c|}{ Model $2^{* *}$} \\
\hline & \multicolumn{4}{|c|}{$\begin{array}{l}\text { Difference in self-reported and directly } \\
\text { measured weight }\end{array}$} & \multicolumn{4}{|c|}{$\begin{array}{l}\text { Difference in self-reported and directly } \\
\text { measured weight }\end{array}$} \\
\hline & \multicolumn{2}{|c|}{ Boys } & \multicolumn{2}{|c|}{ Girls } & \multicolumn{2}{|c|}{ Boys } & \multicolumn{2}{|c|}{ Girls } \\
\hline & $B(k g)$ & $P$ value & $B(\mathbf{k g})$ & $P$ value & $B(\mathbf{k g})$ & $P$ value & $B(\mathbf{k g})$ & $P$ value \\
\hline \multicolumn{9}{|l|}{ Weighing history } \\
\hline Weighed recently & Ref. & & Ref. & & Ref. & & Ref. & \\
\hline Not weighed recently & 0.4178 & 0.3306 & -1.1977 & $<0.0001$ & 0.5586 & 0.1569 & -1.0197 & $<0.0001$ \\
\hline \multicolumn{9}{|l|}{ Recall ability for weight } \\
\hline High & Ref. & & Ref. & & Ref. & & Ref. & \\
\hline Low & -0.5377 & 0.3580 & -1.3932 & $<0.0001$ & -0.2290 & 0.6707 & -0.9902 & 0.0024 \\
\hline \multicolumn{9}{|l|}{ Response capability for weight } \\
\hline Weighed recently + high recall ability & Ref. & & Ref. & & Ref. & & Ref. & \\
\hline Weighed recently + low recall ability & -0.1214 & 0.9055 & -2.1313 & 0.0001 & 0.5085 & 0.5890 & -1.6961 & 0.0008 \\
\hline Not weighed recently + high recall ability & 0.7962 & 0.1108 & -1.3159 & 0.0002 & 0.9603 & 0.0364 & -1.2345 & $<0.0001$ \\
\hline \multirow[t]{4}{*}{ Not weighed recently + low recall ability } & -0.4524 & 0.5145 & -1.2579 & 0.0028 & -0.2233 & 0.7261 & -0.8671 & 0.0240 \\
\hline & \multicolumn{4}{|c|}{$\begin{array}{l}\text { Difference in self-reported and directly } \\
\text { measured height }\end{array}$} & \multicolumn{4}{|c|}{$\begin{array}{l}\text { Difference in self-reported and directly } \\
\text { measured height }\end{array}$} \\
\hline & Boys & & Girls & & & & & \\
\hline & $\mathrm{B}(\mathrm{cm})$ & $P$ value & $\mathrm{B}(\mathrm{cm})$ & $P$ value & $\mathrm{B}(\mathrm{cm})$ & $P$ value & $\mathrm{B}(\mathrm{cm})$ & $P$ value \\
\hline \multicolumn{9}{|l|}{ Height measuring history } \\
\hline Measured recently & Ref. & & Ref. & & Ref. & & Ref. & \\
\hline Not measured recently & -0.1000 & 0.7886 & -0.0002 & 0.9994 & -0.1867 & 0.5996 & 0.0040 & 0.9873 \\
\hline \multicolumn{9}{|l|}{ Recall ability for height } \\
\hline High & Ref. & & Ref. & & Ref. & & Ref. & \\
\hline Low & -0.4949 & 0.1786 & -0.1885 & 0.5077 & -0.5693 & 0.1207 & -0.2105 & 0.4483 \\
\hline \multicolumn{9}{|l|}{ Response capability for height } \\
\hline Measured recently + high recall ability & Ref. & & Ref. & & Ref. & & Ref. & \\
\hline Measured recently + low recall ability & -0.6893 & 0.1552 & 0.0092 & 0.9824 & -0.7789 & 0.1068 & 0.0282 & 0.9459 \\
\hline Not measured recently + high recall ability & -0.0610 & 0.8925 & 0.1533 & 0.6119 & -0.1728 & 0.7010 & 0.1945 & 0.5183 \\
\hline Not measured recently + low recall ability & -0.3046 & 0.5553 & -0.2948 & 0.4287 & -0.4020 & 0.4343 & -0.3449 & 0.3530 \\
\hline
\end{tabular}

Difference in BMI z-score based of self-reported Difference in BMI z-score based of self-reported
and direct measures of weight and height

\begin{tabular}{|c|c|c|c|c|c|c|c|c|c|}
\hline & & \multicolumn{4}{|c|}{ and direct measures of weight and height } & \multicolumn{4}{|c|}{ and direct measures of weight and height } \\
\hline & & \multicolumn{2}{|c|}{ Boys } & \multicolumn{2}{|c|}{ Girls } & \multicolumn{2}{|c|}{ Boys } & \multicolumn{2}{|c|}{ Girls } \\
\hline & & B & $P$ value & B & $P$ value & B & $P$ value & B & $P$ value \\
\hline \multicolumn{10}{|l|}{ BMI response capability*** } \\
\hline & High & Ref. & & Ref. & & Ref. & & Ref. & \\
\hline & Low & 0.0404 & 0.4576 & -0.1252 & 0.0019 & 0.0576 & 0.2684 & -0.1042 & 0.0077 \\
\hline
\end{tabular}
and direct measures of weight and height

* adjusted for age, family occupational social class, family structure and migration. A random effect of school was included to adjust for the design effect introduced by the applied cluster sampling approach.

** adjusted for age, family occupational social class, family structure, migration and direct measure of height and/or weight. A random effect of school was included to adjust for the design effect introduced by the applied cluster sampling approach.

***High BMI response capability = measured recently + high recall ability for height + weighed recently + high recall ability for weight, Low combined response capability = remaining categories.

second participant had low response capability for BMI. Students who reported low recall ability were less likely to report their weight in the survey irrespective of when they were last weighed. The same pattern was found for response capability for height. This indicates that reporting of weight and height depend more on recall ability than on weighing and height measuring history. 
Table 6 Overweight prevalence based on self-reported and direct measures of weight and height by BMI response capability

\begin{tabular}{|c|c|c|c|c|c|c|}
\hline & \multicolumn{3}{|c|}{ Boys } & \multicolumn{3}{|c|}{ Girls } \\
\hline & $\begin{array}{l}\% \text { overweight/ } \\
\text { self-reported }\end{array}$ & $\begin{array}{l}\% \text { overweight/ } \\
\text { direct measures }\end{array}$ & $\begin{array}{l}\text { Absolute } \\
\text { difference }\end{array}$ & $\begin{array}{l}\% \text { overweight/ } \\
\text { self-reported }\end{array}$ & $\begin{array}{c}\% \text { overweight } / \text { direct } \\
\text { measures }\end{array}$ & $\begin{array}{l}\text { Absolute } \\
\text { difference }\end{array}$ \\
\hline & 10.97 & 15.64 & 4.67 & 7.06 & 13.17 & 6.64 \\
\hline \multicolumn{7}{|l|}{$\begin{array}{l}\text { BMI response } \\
\text { capability* }\end{array}$} \\
\hline High & 9.55 & 14.48 & 4.93 & 6.91 & 12.40 & 5.49 \\
\hline Low & 12.71 & 17.06 & 4.35 & 7.27 & 14.09 & 6.82 \\
\hline
\end{tabular}

*High combined response capability $=$ measured recently + high recall ability for height + weighed recently + high recall ability for weight, Low combined response capability $=$ remaining categories.

Both boys and girls underestimated their weight. The average underestimation was relatively small, $0.8 \mathrm{~kg}$ for boys and $1.8 \mathrm{~kg}$ for girls. This difference by gender is in line with a number of previous studies [6,8,9,21,25-27] while other studies find no differences between boys' and girls' reports $[5,7,12,14,23,28]$. Only among girls, a significant larger systematic underestimation of weight was seen among those who are not weighed recently. This result is in line with the findings of the previous Belgian study by De Vriendt (2009) [15]. Significantly larger underestimation was also seen among girls who do not recall their weight. When analysing the combined measure for response capability for weight having 'weighed recently + high recall ability' as the reference group all remaining combinations of weighing history and recall ability show a significantly larger underestimation of weight. While no systematic under- or overreporting of weight by response capability was detected among boys, both among boys and girls the results indicate a larger reporting error (random measurement error) among students with low response capability.

Generally, adolescents tend to overestimate their height $[5,6,8,10-12,28]$ and in the present study this is observed among boys. A few studies show overestimation of height especially among girls [13-15,27]. It is however questionable whether the difference observed in the present study is practically relevant as it does not exceed the precision of the height measures. There was no significant difference between mean self-reported height and mean direct measures of height among girls. The multivariate analyses showed that for both boys and girls neither height measuring history, recall ability for height or response capability for height are systematically related to the difference in self-reported and directly measured height. While no systematic difference in misclassification of height by response capability was detected, both among boys and girls the results indicate a larger random measurement error among students with low response capability.

BMI z-scores were underestimated when based on self-reports of weight and height irrespective of gender and BMI response capability. A gender difference was identified as girls with low BMI response capability systematically underestimated their BMI z-scores more than girls with high BMI response capability. Difference in BMI z-scores among boys did not vary across BMI response capability. These differences by gender are also reflected in the analyses of overweight prevalence. Among boys, the difference in underestimation of overweight prevalence constituted only 0.58 percentage points (with the largest underestimation among boys with high response capability) while the difference constituted 1.33 percentage points among girls when comparing students with low and high BMI response capability. Generally, the overall misclassification of height and weight from self-reported data resulted in an underestimation of the proportion of overweight boys of approximately $5 \%$ and an underestimation of overweight girls of approximately $6 \%$.

Among both boys and girls low response capability seems to be consistently associated with a larger random measurement error while a systematic underestimation of BMI z-score and overweight prevalence due to low response capability was only observed among girls. These finding were due to a systematic underestimation of weight among girls who were not weighed recently and among girls with low recall ability for weight. The results therefore indicate that integrating measures of response capability for weight and height among adolescents in questionnaire surveys may be appropriate for identifying adolescent girls with an increased risk of reporting erroneous information on weight. Following, analyses and conclusions drawn based on self-reported data only can be evaluated and adjusted accordingly, e.g. by comparing analyses conducted with and without inclusion of adolescents with low response capability. One way to benefit from information about response capability is to carry out sub-group analyses among participants with high response capability. If analyses in such sub-groups produce prevalence levels and associations which are very different from analyses on the entire study population, this would be an indication of severe problems of misclassification in 
the entire study population. The present study is however the first of its kind and additional studies in other and less selected populations are needed to generate a more general picture on the influence of response capability for reporting height and weight among adolescent boys and girls. Generally, it should however be prioritized that possible adaptions of study designs are conducted to minimise the proportion of students with low capability for reporting height and weight. One approach could be to encourage participants to weigh and measure themselves prior to data collection. This has been suggested earlier by Wang et al. (2002) [7].

In the presented multivariate analyses measured height and weight were included in the final models. This led to some reduction in estimates indicating that some overlap may exist between the applied measure of response capability and social desirability when adolescents report weight and height. This finding is supported by the fact that overweight prevalence is higher in the groups of students who report not having been measured recently compared to those who are and in the groups of student with low recall ability compared to students with high recall ability. Still, despite adjusting for measured values significantly larger systematic underestimations were seen among girls with low response capability compared to girls with high response capability.

The presented results should be evaluated in light of the methodological approach employed. For the concept of response capability a number of assumptions are made. We define response capability by time since last weighing/ height measure and ability to recall. This approach does not consider other factors including availability and accuracy of home equipment for weighing and measuring, how the weighing and measuring are conducted, and whether the child is aware of the measured values. The participation rate was generally high and we do not anticipate substantial selection bias. However, the study is not representative and the prevalence figures cannot be generalised across populations. We propose repetition of this study in other and less selected study populations.

\section{Conclusion}

The present study showed that one third of students aged 11 to 15 years had low response capability for height and weight when responding in a self-administrated questionnaire survey. Both boys and girls underestimate their weight. Also among both boys and girls the random measurement error tended to be largest among students with low response capability while only among girls with low response capability there was a systematically larger underestimation of weight. Consequently, a similar larger underestimation of BMI z-score and overweight prevalence was found among girls with low response capability. Boys over-reported their height, and for both boys and girls the random measurement error tended to be larger among students with low response capability. For both boys and girls, there was no systematic difference in reporting height by response capability. The present study indicates that this approach may be particularly relevant for studies including self-reported measurements from girls. Repetition of this study in other and less selected study populations is recommended.

\section{Competing interests}

The study was financed by the Nordea Foundation. The Nordea Foundation was not involved in the study design, data analyses or interpretation of results. The authors declare no competing interests.

\section{Authors' contributions}

MR is the principal investigator of the Aarhus School Survey. MR conceived and coordinated the study, contributed to its design, acquisition of data, statistical analyses, interpretation of data and drafted the manuscript. BH co-conceived the study and contributed to its design and coordination and revised the manuscript critically. MTD contributed to the design of the study and to the statistical analyses and revised the manuscript critically. OM contributed to the design of the study, interpretation of data and revised the manuscript critically All authors read and approved the submitted manuscripts.

\section{Acknowledgement}

We thank Trine Pagh Pedersen and Katrine Rich Madsen from our research team and Poul Lundsgaard Bak, Henriette Hansen, Sheila Terp, Anette Østergaard from the City of Aarhus for their important contribution to the planning of the study and data collection. We thank the Nordea Foundation for financial support to the study.

\section{Sources of support}

The Nordea Foundation.

\section{Author details}

${ }^{1}$ National Institute of Public Health, University of Southern Denmark, Øster Farimagsgade 5A, Copenhagen K DK-1353, Denmark. ²Department of Child and Adolescent Mental Health, Norwegian Institute of Public Health, PO Box 4404Nydalen, N-0403, Oslo, Norway.

Received: 13 June 2012 Accepted: 12 June 2013

Published: 27 June 2013

\section{References}

1. Roberts C, Freeman J, Samdal O, Schnohr CW, de Looze m, Nic Gabhainn S, lannotti R, Rasmussen M, The International HBSC study group: The health behaviour in school-aged children (HBSC) study: methodological developments and current tensions. Int J Public Health 2009, 54(Suppl 2):140-150.

2. te Velde SJ, De Bourdeaudhuij I, Thorsdottir I, Rasmussen M, Hagströmer M, Klepp Kl, Brug J: Patterns in sedentary and exercise behaviors and associations with overweight in 9-14-year-old boys and girls-a crosssectional study. BMC Publ Health 2007, 7:16

3. Haug E, Rasmussen M, Samdal O, lannotti R, Kelly C, Borraccino A, Vereecken C, Melkevik O, Lazzeri G, Giacchi M, Ercan O, Due P, RavensSieberer U, Currie C, Morgan A, Ahluwalia N, the Health Behaviour in School-aged Children Obesity Working Group: Overweight in school-aged children and its relationship with demographic and lifestyle factors: results from the $\mathrm{WHO}$-collaborative health behaviour in school-aged children (HBSC) study. Int J Public Health 2009, 54(Suppl 2):167-179.

4. Currie C, Zanotti C, Morgan A, Currie D, de Looze M, Roberts C, Samdal O, Smith ORF, Barnekow V: Social determinants of health and well-being among young people. Health behaviour in school-aged children (HBSC) study: international report from the 2009/10 survey. Copenhagen: WHO Regional Office for Europe; 2012. Health Policy for Children and Adolescents, No. 6.

5. Giacchi M, Mattei R, Rossi S: Correction of the self-reported BMI in a teenage population. Int J Obes Relat Metab Disord 1998, 22:673-677.

6. Rovira RF, Pons IF, Martínes IM, Sánchez RR: Self-reported versus measured height, weight and body mass index in Spanish Mediterranean 
teenagers: effect of gender, age and weight on perceptual measures of body image. Ann Nutr Metab 2002, 46:68-72.

7. Wang Z, Patterson CM, Hills AP: A comparison of self-reported and measured height, weight and BMI in Australian adolescents. Aust N Z J Public Health 2002, 26:473-478.

8. Brener ND, McManus T, Galuska DA, Lowry R, Wechsler H: Reliability and validity of self-reported height and weight among high school students. J Adolesc Health 2003, 32:281-287.

9. Elgar FJ, Roberts C, Tudor-Smith C, Moore L: Validity of self-reported height and weight and predictors of bias in adolescents. J Adolesc Health 2005, 37:371-375.

10. Himes JH, Hannan P, Wall M, Neumark-Sztainer D: Factors associated with errors in self-reports of stature, weight, and body mass index in Minnesota adolescents. Ann Epidemiol 2005, 15:272-278.

11. Janssen W, van de Looij-Jansen PM, Ferreira I, de Wilde EJ, Brug J: Differences in measured and self-reported height and weight in Dutch adolescents. Ann Nutr Metab 2006, 50:339-346.

12. Tokmakidis SP, Christodoulos AD, Mantzouranis NI: Validity of self-reported anthropometric values used to assess body mass index and estimate obesity in Greek school children. J Adolesc Health 2007, 40:305-310.

13. Brettschneider AK, Rosario AS, Ellert U: Validity and predictors of BMI derived from self-reported height and weight among 11- to 17-year-old German adolescents from the KiGGS study. BMC Res Notes 2011, 4:414.

14. Fonseca H, Silva AM, Matos MG, Esteves I, Costa P, Guerra A, Gomes-Pedro J: Validity of BMI based on self-reported weight and height in adolescents. Acta Paediatr 2010, 99:83-88.

15. De Vriendt T, Huybrechts I, Ottevaere C, Van Trimpont I, De Henauw S: Validity of self-reported weight and height of adolescents, its impact on classification into BMI-categories and the association with weighing behaviour. Int J Environ Res Public Health 2009, 6:2696-2711.

16. Hauck FR, White L, Cao G, Woolf N, Strauss K. Inaccuracy of self-reported weights and heights among American Indian adolescents. Ann Epidemiol 1995, 5:386-392

17. Currie C, Nic Gabhainn S, Godeau E and the International HBSC Network Coordinating Committee: The health behaviour in school-aged children: WHO collaborative cross-national (HBSC) study: origins, concept, history and development 1982-2008. Int J Public Health 2009, 54(Suppl 2):131-139.

18. de Onis M, Onyango AW, Borghi E, Siyam A, Nishida C, Siekmann J: Development of a WHO growth reference for school-aged children and adolescents. Bull World Health Organ 2007, 85(9):660-667.

19. Woodward M: Epidemiology: study design and data analysis. 2nd edition. New York: Chapman \& Hall/CRC; 2004

20. Brown H, Prescott R: Applied mixed models in medicine. 2nd edition. England: John Wiley \& Sons Ltd; 2006.

21. Kurth BM, Ellert U: Estimated and measured BMI and self-perceived body image of adolescents in Germany: part 1 - general implications for correcting prevalence estimations of overweight and obesity. Obes Facts 2010, 3(3):181-190

22. Strauss RS: Comparison of measured and self-reported weight and height in a cross-sectional sample of young adolescents. Int I Obes Relat Metab Disord 1999, 23(8):904-908.

23. Morrissey SL, Whetstone LM, Cummings DM, Owen LJ: Comparison of selfreported and measured height and weight in eighth-grade students. J Sch Health 2006, 76(10):512-515.

24. Tsigilis N: Can sedondary school students' self-reported measures of height and weight be trusted? An effect size approach. Eur J Public Health 2006, 16(5):532-535.

25. Shannon B, Smiciklas-Wright H, Wang MQ: Inaccuracies in self-reported weights and heights of a sample of sixth-grade children. J Am Diet Assoc 1991, 91:675-678.

26. Goodman E, Hinden BR, Khandelwal S: Accuracy of teen and parental reports of obesity and body mass index. Pediatrics 2000, 106:52-58.

27. Abalkhail BA, Shawky S, Soliman NK V Validity of self-reported weight and height among Saudi school children and adolescents. Saudi Med J 2002, 23(7):831-837.

28. Fortenberry JD: Reliability of adolescents' reports of height and weight. J Adolesc Health 1992, 13:114-117.

doi:10.1186/1471-2288-13-85

Cite this article as: Rasmussen et al: Validity of self-reported height and weight among adolescents: the importance of reporting capability. BMC Medical Research Methodology 2013 13:85.

\section{Submit your next manuscript to BioMed Central and take full advantage of:}

- Convenient online submission

- Thorough peer review

- No space constraints or color figure charges

- Immediate publication on acceptance

- Inclusion in PubMed, CAS, Scopus and Google Scholar

- Research which is freely available for redistribution 